\title{
Preliminary risk assessment of old landfills in Italy
}

\author{
R. Cossu, A. Pivato \& R. Raga \\ IMAGE - Department of Hydraulics, Maritime, Environmental and \\ Geotechnical Engineering, University of Padua, Italy
}

\begin{abstract}
In the framework of the EU-life Project "Evaluation and first assessment of old deposits", financed by the European Union, the IMAGE Department of the University of Padova carried out a survey for the evaluation of the current situation of old landfills in Southern Europe Countries and in particular in Italy, and the application of a novel risk assessment model proposed by the EVAPASSOLD partners, as a priority ranking system for remediation intervention.

The most significant parameters for the characterization of old landfills were considered, such as: volume and height of landfills, years after landfill closure, waste characteristics, geological situation, presence and characteristics of groundwater and the liquid-solid ratio (L/S), which indicates the amount of rainfall through the landfill body related to the waste mass.

The preliminary risk assessment model was applied to some landfills in northern Italy. The results of monitoring and experimental activities on site were used for the calibration of the proposed model.
\end{abstract}

Keywords: Preliminary Risk, Landfill, EVAPASSOLD

\section{Introduction}

In the framework of the EU-life Project "Evaluation and first assessment of old deposits", the IMAGE Department of the University of Padova carried out a survey for the evaluation of the current situation of old landfills in Southern Europe Countries and in particular in Italy. 


\section{Environmental Health Risk}

In the first part of the study, contacts were established with local and central administrations in Italy, in order to:

- find out if a detailed collection of data on old landfills (containing information on characteristics of the landfill such as bottom liner, age of deposition, waste characteristics, geological situation around the deposit, leachate and biogas emissions, expected long term emissions....) was currently available and the related material was collected;

- find out if any risk assessment procedure had been set up or was under consideration.

In the second part of the study, the application of the model, proposed by the EVAPASSOLD partners for the evaluation and preliminary assessment of old deposits, was carried out. The assessment was conducted not only for the landfills that have been investigated by the IMAGE Department, but also for other old landfills in Italy, for which enough information was available. This was possible thanks to the simple structure of the new first assessment model.

Some comments on the general procedure for risk management of old landfill are given.

\section{Risk Management}

According to the information obtained, in Italy no official risk assessment procedure has been set up and used for the preliminary evaluation of old waste deposits; remediation is currently considered for deposits where at least one of the following conditions occur:

- there is an evidence or at least well-founded suspicions of groundwater contamination;

- there is an evidence or at least well-founded suspicions of uncontrolled biogas migrations into residential areas by the deposit;

- new volumes for waste disposal are necessary and the remediation (i.e. landfill mining) would allow a better utilization of the area and the construction of a new landfill.

However, no priority ranking list has been made and the decisions are made at local level, provided that the necessary funding can be found.

The quantity of data required to carry out a traditional risk assessment for landfills does not allow its implementation in the general context of the Italian situation, as the cost of all the necessary analysis for the identification of the hazard of the system for all the landfills would be not sustainable. In fact, thousands of old landfills in the Italy represent a potential risk for the surrounding environment and for man. However, as suggested by the EVAPASSOLD Project partners, it might be possible to select a number of old landfills for which no further investigations are needed and for which a negligible risk can be considered. These cases have to be selected from those for which the situation is unclear and an evaluation of the potential risk has to be carried out.

An instrument that may be useful to this aim is the preliminary risk assessment as it was proposed by EVAPASSOLD Project partners, that enables 
to evaluate the magnitude of the risk of the system (i.e. the potential hazard of the system) and the vulnerability of the universe, with a low demand of initial data.

In the model the magnitude is evaluated considering the possible attenuation of waste pollution potential caused by waste degradation and prolonged leaching due to rainfall infiltration. For the evaluation of vulnerability information on general environmental condition and utilization of the area are used.

The two values (magnitude and vulnerability) provide a decision matrix that enables to select the situations that need further assessment (Table 1).

Table 1: Decision Matrix for risk assessment as proposed by EVAPASSOLD Project partners

\begin{tabular}{|c|c|c|}
\hline MAGNITUDE & VULNERABILITY & $\begin{array}{c}\text { FURTHER } \\
\text { ASSESSMENT }\end{array}$ \\
\hline High & High & required \\
\hline High & Low & Not required \\
\hline Low & Low & Not required \\
\hline Low & High & Not required \\
\hline
\end{tabular}

The preliminary risk assessment is a decision tool that applies to old landfills; for new landfills a risk assessment should be considered. In fact, old landfills could have been attenuated by the natural degradation processes as well as leaching from rainfall.

Conversely controlled landfills are hardly attenuated by leaching water, and in consequence, are potentially dangerous and must be studied in detail.

In case of intermediate situations where in the same place both an old landfill and a landfill in operation are present, the two cases must be considered separately, according to what indicated in the Figure 1.

\subsection{Field investigations}

A field survey is the base upon which a risk assessment of the system under exam is executed. In particular the following analysis for assessing the hazard of the polluting flows and the attenuating both internal (through the barriers) and external processes (natural attenuation) have to be carried out.

- Historical data analysis: this research aims at compiling all the previous surveys carried out (geological structure of the site, etc) and at identifying the typology and quantity of the landfilled waste;

- Waste analysis: respirometric test $\left(\mathrm{IR}_{4}, \mathrm{IR}_{7}\right)$, fermentation test $\left(\mathrm{B}_{21}\right)$, test for eluates $\left(\mathrm{pH}, \mathrm{COD}, \mathrm{BOD}_{5}, \mathrm{BOD} / \mathrm{COD}, \mathrm{TKN}, \mathrm{NH}_{3}, \operatorname{OrgN}\right.$, Nitrate, trace metals, toxicological tests), Black Index, composition and granulometric analysis;

- Leachate analysis: $\mathrm{pH}, \mathrm{COD}, \mathrm{BOD}_{5}, \mathrm{BOD} / \mathrm{COD}, \mathrm{TKN}, \mathrm{NH}_{3}, \operatorname{OrgN}$, Nitrate, trace metals, toxicological tests, pumping tests; 


\section{Environmental Health Risk}

- Biogas analysis: biogas quality, assessment of uncontrolled gas migration through the landfill cover and the lateral barriers; assessment of the efficiency of the biogas extraction systems;

- Barriers analysis: analysis of the characteristics and of the attenuating capacity of the clay liner.

The results of the investigations are needed for the calibration of the risk assessment model. For this purpose, five landfills (Modena, Legnago, Torino, Campodarsego and Chioggia) in northern Italy were extensively investigated .

\subsection{Application levels of risk assessment}

The prearranged procedures for the utilisation of risk assessment take into account simplified intermediate levels, and in consequence, a gradual approach; passing from a level to another:

- The protection level of health of man and the environment remains unaltered;

- The number of parameters and surveys increase;

- The quantity of technical and economical resources increase;

- Economic efficiency of the interventions;

- The conservative assumption decreases.

The preliminary risk analysis can be regarded as a Level Zero for the landfill system, where it is essential to identify only the potentiality hazard, with measures easily available.

The Level one consists of confronting the contamination of the site with the screening values and locating the targets in the proximity of the source. The screening values consider the toxicological data of the substances and the diverse exposition ways that can be activated according to different land uses, but do not take into consideration the local data of the site. From the confrontation between the contamination of the site and the screening values it may be decided either:

- The site can be dismissed as non contaminated;

- It is necessary to remediate up to the screening values.

In order to take the surveys and assessment further it is required to pass to a successive level. In these steps it is planned to locate the exposition and conformity points beyond the polluting source and not immediately over it.

In Level Two the deeper surveys in the site provide information needed for:

- The conceptual model

- The chemical, physical and environmental parameters that determine the migration and the parameters of local exposition.

Level three is applicable when neither Level 2 nor Level 3 are adequate for the specific conditions of the site. In this level the objectives of remedation are set by means of more complex analysis that may utilise more sophisticated models for the simulation of transport and fate of pollutants. In this level a probabilistic approach can be used. 


\section{Conceptual Model for Preliminary Risk Assassment}

The new first-evaluation model, was created by the EVAPASSOLD Project partners for the assessment of small old deposits, in order to identify the environmental risk of the landfill system. In particular, the model was created for application to old landfills smaller than $50.000 \mathrm{~m}^{3}$ and with an average thickness up to $8 \mathrm{~m}$; but it was actually tested in case of higher volumes also.

The Risk $(R)$ is calculated considering three factors: Ro, $f(L / S)$ and $f(G)$, as $\mathrm{R}=\mathrm{Ro} * \mathrm{f}(\mathrm{L} / \mathrm{S}) * \mathrm{f}(\mathrm{G})$.

Ro deals with the historical background of the old deposits, and its value is fixed according to the kind of deposited waste. The liquid-to-solid ratio is related to the age and waste biochemical stability in the old deposit. Finally, the $f(G)$ factor considers the general environmental condition and utilization of the area of the old deposit.

In this case the magnitude is represented by two parameters Ro e $F(L / S)$ while the vulnerability of the system by $f(G)$.

\subsection{The $\mathbf{R}_{0}$ factor}

$R_{0}$ is a parameter that considers the type of waste. This first first model doesn't include two particular waste categories: completely inert waste (low magnitude) and waste with a percentage of hazardous waste higher than $1 \%$ (high magnitude). In the other cases, for this parameter the following values can be considered:

- Construction waste, excavation materials with $10 \%$ of domestic waste: $\mathrm{R}_{0}=1,1(20 \%=1,2 ; 30 \%=1,3)$;

- $100 \%$ domestic waste and domestic-like commercial waste: $\mathrm{R}_{0}=2$ (containing a maximum of $1 \%$ hazardous waste).

According to this scheme, $\mathrm{R}$ only gets evaluated, if $\mathrm{R}_{0}$ has a value between 1 and 2 .

\subsection{The $f(L / S)$ (Liquid/solid) factor}

In order to simplify the application of this model, the following Table 2 has been developed for the determination of the function of liquid-to-solid ratio.

Table 2: Summary of parameters for the evaluation of Liquid/solid factor

\begin{tabular}{cc|}
\hline $\mathbf{L} / \mathbf{S}$ & $\mathbf{F}(\mathbf{L} / \mathbf{S})$ \\
\hline $\mathrm{L} / \mathrm{S}<1$ & 1 \\
\hline $1<\mathrm{L} / \mathrm{S}<5$ & $1,2143-0,1429 *(\mathrm{~L} / \mathrm{S})$ \\
\hline $\mathrm{L} / \mathrm{S}>5$ & 0.5 \\
\hline
\end{tabular}

The actual water infiltration (L) into the landfill should be calculated; the mass of waste present in the old deposit $(\mathrm{S})$ has to be estimated according to the information available. The calculation of $\mathrm{L}$ has been made by means of a model 


\section{Environmental Health Risk}

(Cossu and Pivato, 2002) that considers the most important factors influencing evapo-transpiration, surface runoff, and infiltration. The parametr $\mathrm{S}$ is the mass of waste inside the landfill. High values of the $\mathrm{L} / \mathrm{S}$ ratio means that the deposited waste have been considerably leached during the operative and post closure phase; in case of low values, a higher amount of degradable organics can still be expected to be found in the waste and the associated potential hazard is expected to be high.

\subsection{The $f(G)$ factor}

The $f(G)$ factor considers the general environmental condition and utilization of the area of the old deposit. Therefore, an evaluation can be performed on basis of groundwater, surface water, air and soil. The corresponding evaluation parameters are presented in Table 3. High values of the parameter $f(G)$ are given in case of high vulnerability

Table 3 - Summary of parameters for the evaluation of the factor $f(G)$

\begin{tabular}{|c|c|}
\hline & Parameters for the evaluation of $\mathrm{f}(\mathrm{G})$ for groundwater \\
\hline 1 & no utilization possibilities for groundwater \\
\hline 1,3 & Within influence area of water well \\
\hline 1,5 & $\begin{array}{l}\text { run-off water, pore groundwater,... sufficient only for individual and/or local } \\
\text { water supplies. }\end{array}$ \\
\hline 1,7 & Inside a (potential) area of regional and/or national drinking water supply \\
\hline 1,8 & $\begin{array}{l}\text { all declared sanctuaries and protected areas (phase III), groundwater body with } \\
\text { national importance }\end{array}$ \\
\hline 2 & all declared sanctuaries and protected areas (phase I + II) \\
\hline$>2$ & in area of influence of an actual drinking water supply \\
\hline $7=$ & Parameters for the evaluation of $\mathrm{f}(\mathrm{G})$ for surface water \\
\hline 1 & $\begin{array}{l}\text { no surface-water within } 25 \mathrm{~m} \text { surrounding and surface-water with possibility } \\
\text { of contact to humans no more than after huge thinning of a potential emission } \\
\text { and surface water without any special utilisation claim. }\end{array}$ \\
\hline 1,5 & $\begin{array}{l}\text { surface water within directly urban areas or leisure areas (or in nature reserve), } \\
\text { larger thinning possible. }\end{array}$ \\
\hline 2 & $\begin{array}{l}\text { surface waterwithin directly urban areas or leisure areas (or in nature reserve), } \\
\text { no larger thinning probable resp. utilisation for in-shore filtration recovery or } \\
\text { ground water-accumulation }\end{array}$ \\
\hline & Parameters for the evaluation of $f(G)$ for air \\
\hline 1 & No utilization possible and/or contact with humans improbable. \\
\hline 1,2 & Utilization possible (e.g. grassland) and/or contact with humans possible \\
\hline 1,5 & $\begin{array}{l}\text { actual agricultural utilization (e.g. plant production) or location in a natural } \\
\text { reserve, eventual fixtures in this area. }\end{array}$ \\
\hline 1,7 & $\begin{array}{l}\text { single urban areas and/or other buildings or facilities for humans as well as } \\
\text { leisure areas (park) }\end{array}$ \\
\hline 2 & $\begin{array}{l}\text { directly urban areas and/or areas with high sensible utilization (e.g. children's } \\
\text { playground) }\end{array}$ \\
\hline & Parameters for the evaluation of $\mathrm{f}(\mathrm{G})$ for soil \\
\hline 1 & No possible use of surface. \\
\hline
\end{tabular}


Environmental Health Risk 201

\begin{tabular}{|l|l|}
\hline 1,2 & agricultural utilization of surface possible. \\
\hline 1,5 & agricultural utilization of surface or situation within natural reserve. \\
\hline 1,7 & In urban areas without possibility of direct contact to children. \\
\hline 2 & $\begin{array}{l}\text { Usage of area and/or usage of direct surrounding as leisure area (also } \\
\text { children's playground). }\end{array}$ \\
\hline
\end{tabular}

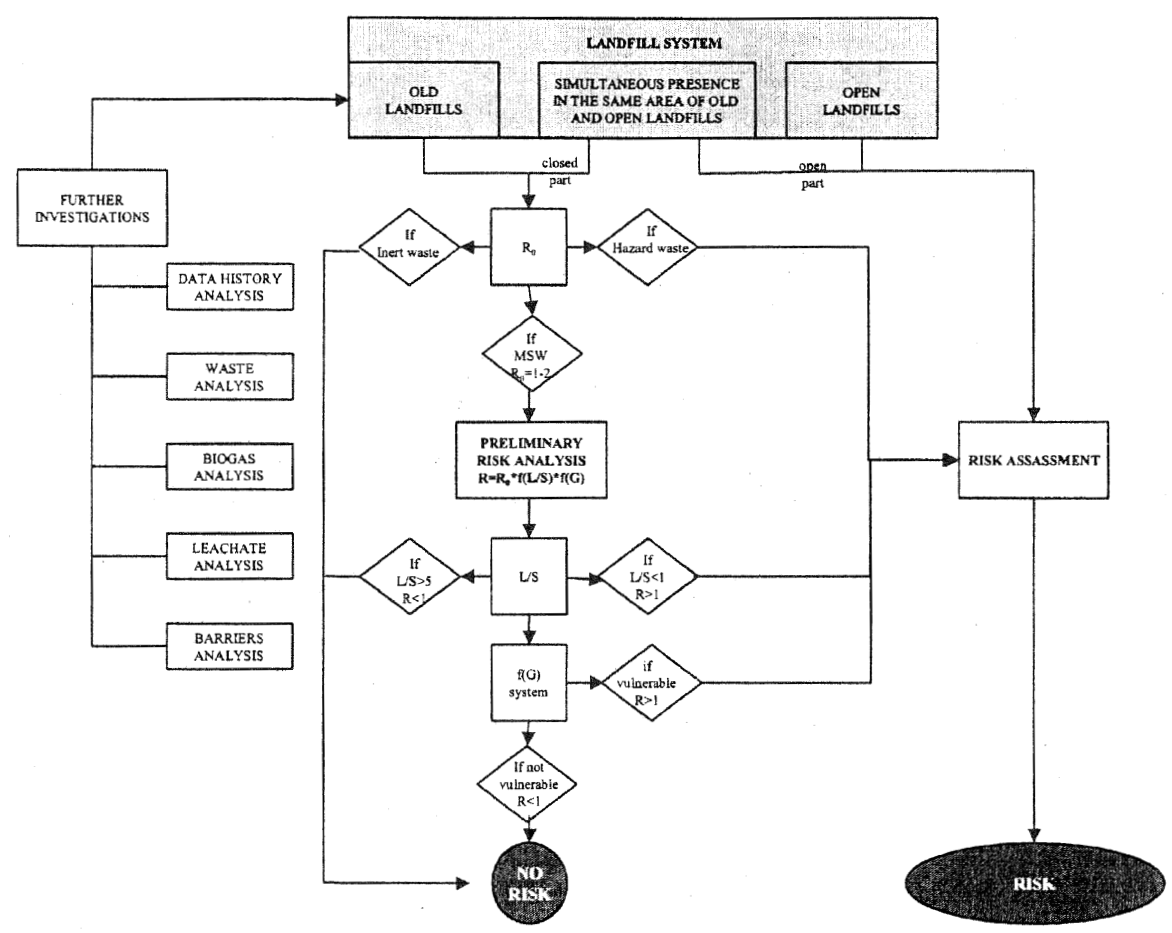

Figure 1: Preliminary risk assessment scheme

\section{Application of the First Evaluation Model to Landfills in Italy}

The evaluation of potential hazard of different types of landfill sites have been carried out by means of the new first evaluation model, proposed by the partners of the EVAPASSOLD project. The following landfills were considered as samples: Campodarsego, Chioggia, Legnago, Noale, Portogruaro (2 landfills) (north-eastern Italy); Torino, Cassolnovo, Zerbo (north-western Italy); Modena, Pisa (Central Italy); Gricignano, Succivo (2 landfills) Mondragone (southern Italy). 


\section{Environmental Health Risk}

Risk $\mathrm{R}$ was calculated, according to the model, as $\mathrm{R}=\mathrm{Ro} * \mathrm{f}(\mathrm{L} / \mathrm{S}) * \mathrm{f}(\mathrm{G})$. The evaluation was possible considering the information available on the characteristics of waste and deposit and the environmental data.

The evaluation of $f(G)$ was carried out in some cases thanks to information collected directly at the single municipalities; in other cases data from actual investigations carried out by the IMAGE Department were used. A brief description of the considered landfills is below and the values chosen for parameter $f(G)$ are reported.

The calculation of risk has been carried out and the results are given below as table (Table 4) and figure (Figure 2). Some remarks follows.

Table 4 - Values of the parameters for risk calculation and Risk for groundwater, surface water, soil and air.

\begin{tabular}{|c|c|c|c|c|c|c|c|c|c|c|c|}
\hline \multirow[t]{2}{*}{ Location } & \multirow[t]{2}{*}{ Ro } & \multirow[t]{2}{*}{$f(L / S)$} & \multirow[t]{2}{*}{$\begin{array}{c}\text { actual material } \\
\text { hazard }\left(\mathrm{Ro}^{*} \mathrm{~F}(\mathrm{~L} / \mathrm{S})\right)\end{array}$} & \multicolumn{4}{|c|}{$f(G)$} & \multicolumn{4}{|c|}{$R$} \\
\hline & & & & $\overline{G W}$ & SW & A & $\mathrm{S}$ & GW & SW & A & $S$ \\
\hline Campodarsego & 2,00 & 1,00 & 2,00 & 1,00 & 1,50 & 1,00 & 1,00 & 2,00 & 3,00 & 2,00 & 2,00 \\
\hline Chioggia & 2,00 & 1,00 & 2,00 & 1,80 & 2,00 & 1,00 & 1,00 & 3,60 & 4,00 & 2,00 & 2,00 \\
\hline Legnago & 2,00 & 1,00 & 2,00 & 1,50 & 1,00 & 1,00 & 1,00 & 3,00 & 2,00 & 2,00 & 2,00 \\
\hline Noale & 2,00 & 0,50 & 1,00 & 1,00 & 1,00 & 9,00 & 1,00 & 1,00 & 1,00 & 1,00 & 1,00 \\
\hline Portogruaro a & 2,00 & 0,94 & 1,88 & 1,00 & 1,00 & 1,00 & 1,00 & 1,88 & 1,88 & 1,88 & 1,88 \\
\hline Portogruaro b & 2,00 & 1,00 & 2,00 & 1,00 & 1,00 & 1,00 & 1,00 & 2,00 & 2,00 & 2,00 & 2.00 \\
\hline Torino & 2,00 & 1,00 & 2,00 & 1,00 & 1,00 & 1,00 & 1,00 & 2,00 & 2,00 & 2,00 & 2.00 \\
\hline Cassolnovo & 1,80 & 0,68 & 1,23 & 1,70 & 1,50 & 1,00 & 1,00 & 2,09 & 1,85 & 1,23 & 1,23 \\
\hline Zerbo & 1,80 & 0.50 & 0,90 & 2,00 & 1,20 & 1,20 & 1,20 & 1,80 & 1,08 & 1,08 & 1,08 \\
\hline Modena & 2,00 & 1,00 & 2,00 & 1,00 & 1,00 & 1,00 & 1,00 & 2,00 & 2,00 & 2,00 & 2,00 \\
\hline Pisa & 1,80 & 0,75 & 1,35 & 2,00 & 2,00 & 1,20 & 1,20 & 2,70 & 2,70 & 1,62 & 1,62 \\
\hline Gricignano & 2,00 & 0,50 & 1,00 & 1,00 & 1,00 & 1,20 & 1,20 & 1,00 & 1.00 & 1,20 & 1,20 \\
\hline Succivo a & 1,80 & 0,50 & 0,90 & 1,00 & 1,00 & 1,50 & 1,50 & 0,90 & 0,90 & 1,35 & 1,35 \\
\hline Succivo b & 1,80 & 0,50 & 0,90 & 1,00 & 1,00 & 1,20 & 1,20 & 0,90 & 0,90 & 1,08 & 1,08 \\
\hline Mondragone & 2,00 & 0,50 & 1,00 & 1,00 & 1,00 & 1,20 & 1,20 & 1,00 & 1,00 & 1,20 & 1,20 \\
\hline
\end{tabular}

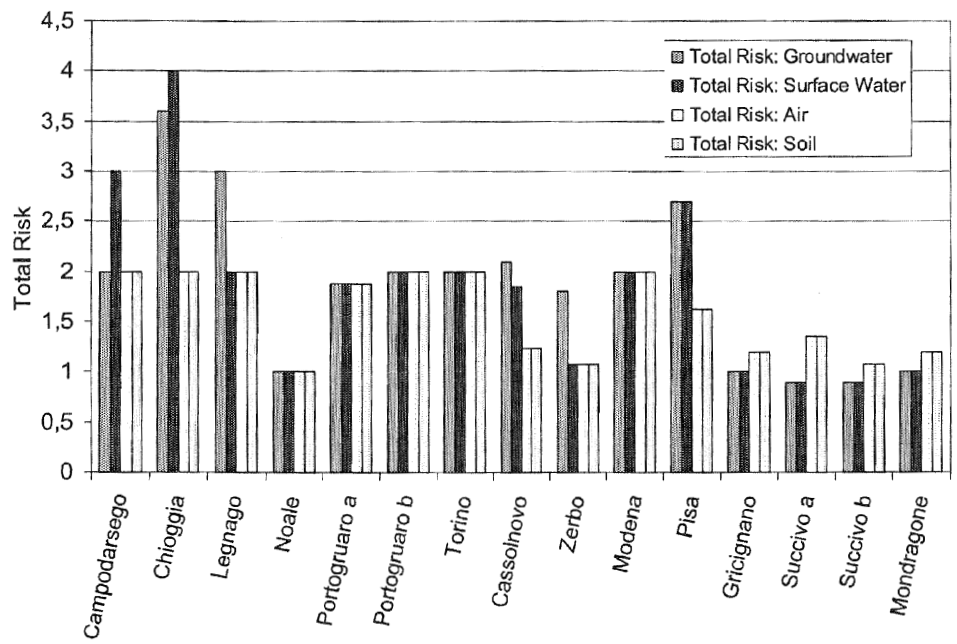

Figure 2 - Overview of total risk for groundwater, surface water, air and soil as calculated in the considered landfills. 


\section{Discussion of the Results and Conclusions}

- According to the instructions for the application of the model, only landfills smaller than $50.000 \mathrm{~m}^{3}$ and with an average thickness up to $8 \mathrm{~m}$ should be considered. However, the model was tested with different landfills and seems to be applicable no matter what the size and depth of the landfills are.

- During the study, it was possible to collect information for 1200 landfills in Italy but only for $20 \%$ of them data on waste volume and depth were available. However, after the recent publication of the National Guidelines for the compilation of old landfill and contaminated sites data base in Italy, the local administration are making further steps in the acquisition of relevant data from the municipalities and they are organizing them by using appropriate software (georeferenced data will soon be available). Better possibilities for the application of the model can be expected in the near future.

- In order to improve its versatility, the use of the preliminary assessment model should be possible in the case of contemporary presence in the same area of old waste deposits and controlled landfills. The case of new landfills built as an extension of old waste deposits is very frequent in Italy (Basse di Stura, Campodarsego, Legnago, Modena, Portogruaro). In this situation, the evaluation of risk and the definition of strategies for intervention should be carried out considering the area as a whole. The preliminary assessment scheme might be applied to the old deposit and the risk assessment might be carried out as suggested in the flow chart in Figure 1.

- The application of the model gives the result that some landfills present values of $\mathrm{R}$ higher than 1 , so they need further investigations.

- The laboratory and field analysis carried of for the landfills of Campodarsego, Legnago, Chioggia, Modena and Torino, produced results consistent with the results of the application of the model.

\section{References}

EVAPASSOLD, "Evaluation of the current state of old landfill sites in Southern Europe", Final Project made by Department Image, Jenuary 2003.

Cossu R. e Pivato.A, "Produzione di percolato e Biogas", in Seminario di Aggiornamento "La Bonifica delle Vecchie Discariche", Aula Magna della Facoltà di Ingegneria, Padova; 10 - 12 Giugno 2002. 
